**In Press at Cultural Diversity and Ethnic Minority Psychology

\title{
Children's cross-cultural categorizations of racially ambiguous faces in Taiwan and the
}

\section{U.S.}

\author{
Sarah E. Gaither, ${ }^{1}$ Chun-Man Chen, ${ }^{2}$ Samantha Neal, ${ }^{1}$ and Sarina Hui-Lin Chien ${ }^{2,3,}{ }^{*}$ \\ ${ }^{1}$ Department of Psychology and Neuroscience, Duke University, Durham, NC, U.S.A. \\ ${ }^{2}$ Graduate Institute of Biomedical Sciences, China Medical University, Taichung, \\ Taiwan \\ ${ }^{3}$ Graduate Institute of Neural \& Cognitive Sciences, China Medical University, \\ Taichung, Taiwan
}

Word count (text+abstract): 11,101

\begin{abstract}
Author Note
Sarah E. Gaither and Chun-Man Chen both contributed equally to this work and are cofirst authors. This work was supported in part by the Taiwanese Ministry of Science and Technology Grants: MOST 103-2410-H-039-002-MY3, MOST 105-2632-B-039-003 awarded to S.H.L. Chien; MOST 106-2912-I-039-502 awarded to S.H.L. Chien and S.E. Gaither, in addition to a grant from the Undergraduate Research Support Office at Duke University awarded to S. Neal. The authors would also like to thank all the adult and child participants and their parents for joining the study.

Correspondence concerning this article should be sent to Dr. Sarina H.L. Chien, Graduate Institute of Biomedical Sciences, China Medical University, No.91 Hsueh-Shih Road, Taichung, Taiwan 40402, R.O.C; Email: sarinachien@ mail.cmu.edu.tw, Tel: 886-0422053366 ext 8202
\end{abstract}




\begin{abstract}
Objectives: Racially ambiguous face categorization research is growing in prominence, and yet the majority of this work has focused on White and Western samples and has primarily used biracial Black/White stimuli. Past findings suggest that biracial Black/White faces are more often seen as Black than White, but without testing these perceptions with other groups, generalizability cannot be guaranteed. Methods: We tested 3-7-year old Asian children living in Taiwan — an Eastern cultural context $(N=74)$ — and Asian children living in the U.S.—a Western cultural context $(N=65)$ to explore the role that cultural group membership may play in biracial perceptions. Children categorized 12 racially ambiguous biracial Black/White faces and 12 biracial Asian/White faces in a dichotomous forced-choice task and completed a racial constancy measurement. Results: Regarding biracial Black/White faces, Taiwanese and Asian American children both categorized the faces as White significantly more often compared to chance levels, regardless of racial constancy beliefs. For biracial Asian/White faces, Taiwanese children with racial constancy beliefs categorized the faces significantly more often as White, whereas Taiwanese children without racial constancy beliefs categorized the faces significantly more often as Asian. However, Asian American children did not show a bias in categorizing biracial Asian/White faces. Conclusions: Results suggest that hyperdescent over hypodescent for more commonly studied biracial Black/White faces generalizes in both cultural contexts. However, biracial Asian/White stimuli may be
\end{abstract}


perceived in more fixed-like patterns in predominately Asian contexts, since only Taiwanese children showed increased outgroup categorizations once racial constancy beliefs were endorsed.

Keywords: ambiguous, face perceptions, cross-cultural, biracial, social development

\section{Public Significance Statement}

Social categorization abilities develop early on in childhood, and yet there remains little research that tests these processes cross-culturally. This skill is essential for our social worlds since we constantly seek out perceptual cues to determine if someone is similar or dissimilar to us (our ingroup versus our outgroup). However, racially ambiguous or raciallymixed faces complicate these perceptions. With the biracial and biethnic populations representing the fastest growing youth groups globally, it is critical for more cross-cultural research to document developmentally when and how we see ambiguous faces across different cultural contexts so we know what may be universal for our social perceptions. 


\section{Children's cross-cultural categorizations of racially ambiguous faces in Taiwan and the U.S}

Face processing and social categorization are critical social skills that develop early on in childhood, where we as perceivers seek out perceptual cues that tell us if someone else is similar or dissimilar to ourselves (our ingroup versus our outgroup). For example, when someone sees a new person, specific features present in that person's face (e.g., racially prototypical facial features such as hair and skin tone; Macrae \& Bodenhausen, 2001; Maddox \& Gray, 2002; Stepanova \& Strube, 2012) influences that categorization automatically. However, as race becomes more ambiguous (i.e., a blend of different racially prototypical features), this makes the perceptual cues more equivocal and thus those faces become significantly more difficult to categorize (Blascovich et al., 1997; Chen \& Hamilton, 2012; Freeman et al., 2010; Gaither et al., 2016).

Developmentally children also show similar categorization processes in weighing skin tone and other facial features as salient markers of group membership when considering ambiguous stimuli as either their ingroup or outgroup (e.g., Chen et al., 2019; Dunham et al., 2015, 2016; Gaither et al., 2014; Roberts et al., 2019), suggesting this process is somewhat universal across the lifespan. However, to date, there has been little racially ambiguous perception work with racial minority samples, child samples, and even less cross-cultural comparisons to empirically assess this potential universality of ambiguous categorization outcomes. 


\section{Potential Categorization Processes}

There are many factors outside of perceptual features that may shift ambiguous face categorization. Here, we focus on racial essentialism or racial constancy - the perception of the inalterability of group membership within the domain of race (Gelman, 2003; Medin \&

Ortony, 1989; Rothbart \& Taylor, 1992) —which has been previously highlighted as a unique predictor of racially ambiguous categorization. For example, adults high in racial essentialism believe that the boundaries between racial groups are distinct (e.g., Chen \& Hamilton, 2012; Plaks Malahy, Sedlins, \& Shoda, 2012) and thus tend to use hypodescent or a "one drop rule" when categorizing racially ambiguous others (e.g., Chao, Hong, \& Chiu, 2013; Ho, Roberts, \& Gelman, 2015; Roberts, Ho, Kteily, \& Gelman, 2021).

Hypodescent is commonly referred to in the U.S. literature as the tendency to categorize individuals with mixed-race ancestry into their socially subordinate group (e.g., Davis, 1991; Ho et al., 2011). Following hypodescent, a perceiver would be more likely to categorize a biracial Black/White face as Black (lower status racial group). However, hypodescent findings have primarily focused on WEIRD samples (White, Educated, Industrialized, Rich, and Democratic), meaning that we do not know if hypdodescent processes also apply to racial/ethnic minorities or non-Western perceivers (Chen, 2019; Henrich et al., 2010). In fact, a recent meta-analysis of mixed-race categorization outcomes highlights that the majority of studies have not examined participant race as a factor, $71 \%$ of all participant samples were 
U.S. based, and hypodecent is only seen if the entire participant sample is White, the stimuli used are biracial Black/White male faces, and a force-choiced dichotomous categorization task is used. This suggests that hypodescent is far from a universal process.

In contrast, the ingroup over-exclusion effect (I.O.E.; Leyens \& Yzerbyt, 1992; Yzerbyt et al., 1995), which is more commonly used in the European ambiguous categorization literature, argues that ambiguous targets are more often categorized as one's most salient outgroup (not necessarily as a lower status group). This effect is often described as the tendency for people to exclude ambiguous individuals from their ingroup in order to protect their own ingroup's distinctiveness. Thus, if hypodescent patterns are present in some populations (e.g., White), but not others, the IOE may be a better or more universal predictor.

Therefore, both hypodescent and I.O.E. would argue that perceiver race should affect categorization outcomes, and yet there is little empirical work that has directly compared these processes. Moreover, the racial background of the biracial targets themselves may also affect categorizations. For example, the historical Black-White divide in the U.S. has created a focus on biracial Black/White stimuli in the field and also may create a Black racial group saliency as a minority group in comparison to thinking about Black people outside of a U.S. framework. In fact, past work shows that even within the U.S., biracial Black/White targets are more likely to be categorized as their minority group (i.e., Black, following a hypodescent argument broadly or the I.O.E. if considering White perceivers) compared to Asian/White 
targets (Ho et al., 2011). Therefore, it is plausible that participant race, target race, and one's cultural context all may influence racially ambiguous categorizations.

\section{Developmental and Cultural Considerations}

Importantly, the majority of racially ambiguous categorization research has also focused on adults (e.g., Halberstadt et al., 2011; Ho et al., 2013; Skinner \& Nicolas, 2015), meaning there is less work about children's perceptions (e.g., Roberts \& Gelman, 2015). This is a critical oversight, since the racial perceptions we form as children often carry over into adulthood. One of the most related published findings shows that White children's adopted of racial constancy beliefs shifts how they categorize and remember racially ambiguous facesWhite children see biracial Black/White faces more often as Black or as their outgroup after adopting of this adult-like thinking about race (Gaither et al., 2014). This suggests a cognitive shift developmentally at least for White children on how they process racially ambiguous others, but this link has not been tested with other racial groups. Other work has also shown that a predominately White sample of children see the Asian-White category boundaries differently than Black-White category boundaries since attention not features other than skin color may develop later (Dunham, Dotsch, Clark, \& Stepanova, 2016).

Moreover, as of 2017 , only $10 \%$ of all developmental papers have featured non-Western participants, with only $4.37 \%$ of all published child participants residing in Asia (Nielsen et al., 2017). Pauker and colleagues (2016) found that children in Hawaii endorse less racial 
essentialist beliefs compared to children in the mainland U.S., and Chen and colleagues (2017) highlighted cultural differences for adults in the U.S. and Brazil regarding how each cultural context sees biracial faces differently. Additionally, in two recent studies, Taiwanese adults and older children tended to categorize biracial Asian/White faces as White (their outgroup; Chen et al., 2016; Chen et al., 2019), following the IOE likely due to Taiwanese individuals being the majority group in that context. As additional evidence for this potential contextual difference, eye tracking work has demonstrated that Chinese individuals scan own- and other-race faces differently-Chinese individuals scan more of the central region of Chinese faces, but focus more of the eyes of White faces (Blais et al., 2008; Fu et al., 2012). Moreover, when Chinese participants thought a racially ambiguous face was their ingroup (Chinese) they also showed the same central region scanning approach, but when that face was seen as their outgroup (White) they switched their scanning patterns, suggesting different visual motivations in categorizing racially ambiguous Asian/White faces (Lee et al, 2013).

\section{The Current Studies}

Thus, to directly test these holes in the literature, here we cross-culturally and empirically tested Asian children living in an Eastern context (e.g., Taiwan) and Asian children living in a Western context (e.g., the U.S.) on how they perceive both biracial Black/White and Asian/White faces — the two most commonly studied biracial stimuli. Study Contexts: Taichung, Taiwan, and Durham, NC, U.S.A. 
In a global comparison of racial/ethnic diversity, the U.S. ranks in the middle of the spectrum, while Asian countries are more ethnically homogenous (Fisher, 2013). Specifically, Taiwan has a majority Han Chinese population (95\%), a small minority of indigenous Malayo-Polynesian people (approximately 2\%), and about 3\% foreign immigrants of various ethnicities (Caucasian, Black, South-East Asians; Ministry of Foreign Affairs, 2018). Despite some brief early Western influence (Andrade, 2010), Taiwan has been controlled by or in economic partnership with Asian nations such as China, Korea, and Japan. Thus, it is likely that people living in Taiwan have moderate exposure to White or Black individuals via media, but little direct or in-person exposure to White or Black individuals (Ministry of Foreign Affairs, 2018; also see Renolds, T., 2020).

In the U.S., the biracial population has increased by $32 \%$ across $2000-2010$, making the biracial population the fastest-growing youth demographic in the country (Jones \& Bullock, 2012; U.S. Census, 2012). During this same time frame in North Carolina, the biracial population increased from 1.3 percent to 2.2 percent, and the Asian population saw an $85 \%$ growth (Yee, 2016). In Durham, North Carolina, U.S.A. Asian individuals make up approximately $5 \%$ percent of the population (the rest of the population breaks down as follows: 42\% White, 41\% Black, 14\% Hispanic/Latino, and 3\% mixed-race; Durham, NC 2010 Census). Therefore, comparing Taiwanese children who are the majority group in an ethnically homogeneous context cross-culturally with Asian American children who are racial 
minorities in a racially heterogeneous context will allow us test how both cultural and racial group status may differentially shape children's biracial categorizations.

\section{Predictions}

Following a hypodescent framework, we would expect children to categorize biracial Black/White faces as Black and biracial Asian/White faces as Asian (the lower status racial group in each case). However, the I.O.E. would instead predict Asian children categorizing biracial Asian/White faces more ofen as White (their outgroup), but would not have a strong prediction for biracial Black/White faces since both racial categories reflect racial outgroups. In fact, based on a recent meta-analysis, the limited set of studies with perceiver race as part of the study design, Black participants have only categorized Black/White targets, and Asian participants only categorized Asian/White targets, which prevents any strong theoretical predictions for a dual-outgroup categorization choice based on past work (Young et al., 2021).However, since Taiwan (and China) tends to emphasize White or Western culture as a superior group or race (Dikötter, 1992; 1997), combined with recent media analyses stressing the negative portrayals of Black or African individuals (Li, Ma, \& Xue, 2009), we argue that the White categorization choice would reflect a more dominant outgroup thanBlack would for Taiwanese children (Lan, 2011; Hung, 2021). Similarly, as a racial minority group in the U.S., Asian American children also see White as their dominant outgroup. Thus, in line with the I.O.E., we predicted that both Taiwanese and Asian American children would categorize 
biracial Black/White faces more often as White - the dominant outgroup in both cultural contexts (Chen, 2012; Hsu, Hsiung, \& Chien, 2017).

However, past work has also suggested that one's social status may also shift whether you consider an ambiguous group member as your ingroup or outgroup based on one's need for maintaining one's status when under threat (e.g., Leonardelli et al., 2010). Specifically, being a majority (Taiwanese children in Taiwan) versus a minority group (Asian American children in the U.S.) member could shift whether children want to exclude or include an ambiguous Asian/White individual. Past work highlights two responses when under threat that vary based on one's social status-you either reaffirm your sense of self by creating more rigid or ingroup favoring social boundaries which is more often seen by high status groups (i.e., seeing someone more often as an outgroup to maintain your status quo), or you become more inclusive to build up your lower status group in either size or power (i.e., seeing someone more easily as an ingroup member; Leonardelli, et al., 2010; Maner et al., 2007; Navarette et al., 2004). Although there is little empirical evidence testing these outcomes, Gaither et al. (2016) demonstrated that both White and Black adult participants were more likely to see a racially ambiguous Black/White biracial face as Black when under threat but for different reasons-White participants wanted to reaffirm their high status so they excluded ambiguous individuals more often, but Black individuals wanted to build up their group's strength by being more inclusive. Thus, majority group members should want to 
maintain their group's status more than minority group members (e.g., Pratto, Sidanius, \& Levin, 2006).

Therefore, regarding biracial Asian/White faces, we expected Taiwanese children to categorize them more often as White to maintain their majority group status compared to Asian American children who we expected to be more flexible on including ambiguous group members. However, we did not expect these majority and minority status differences to influence perceptions of biracial Black/White faces, since neither categorization would be associated with a group maintenance or social belonging motivation.

Finally, knowing that racial constancy beliefs not only shift White adult and children's racially ambiguous categorizations (Chen \& Hamilton, 2012; Gaither et al., 2014), but also White children's prosocial behaviors (Gaither, Perlin, \& Doan, 2020), we also wanted to test whether racial constancy endorsements generalized to an racial/ethnic minority sample and to populations outside of the U.S.. Thus, children between the ages of 3-7 years were recruited since it is across those years that racial constancy understandings start to form at least in U.S. samples (e.g., Gaither et al., 2014; Gaither et al., 2020; Pauker et al., 2014). However, we did not have clear predictions about racial constancy's influence on categorization outcomes since it was unclear how a U.S.-based measurement of racial knowledge that has been tested primarily on White U.S. children may translate to racial minorities in both a Western and an Eastern context. 


\section{Stimuli}

To increase the ecological validity of the categorization outcomes in both cultural contexts combined with recent reviews stating only $16 \%$ of biracial categorization research uses photos of actual biracial people (Chen et al., 2021; Ma et al., 2020), here we used a set of 16 racially ambiguous biracial Black/White and 16 racially ambiguous biracial Asian/White real faces. The biracial Black/White stimuli were previously pre-tested for another project (see Gaither et al, 2018 for method details). To create a novel biracial Asian/White stimuli set, 39 self-identified biracial Asian/White individuals were recruited in the U.S. and were photographed following the same methods used for Gaither et al., 2018. Since there was ethnic variation (e.g., East Asian, Southeast Asian, South Asian) combined with race and ethnicity being uniquely constructed in the U.S., adult raters were recruited in both Taiwan ( $n=32$ mono-ethnic East Asian) and the U.S. (21 White, 17 Asian, 3 Black, 3 Hispanic/Latino, 2 biracial White/Hispanic) to pre-test all photos via an online survey to ensure that racial ambiguity was seen equivalently in both cultural contexts. Our goal was to select 12 photos from this set of 39 that were seen as equally racially ambiguous as either Asian or White for both Taiwanese and American individuals. Participants rated all 39 faces in a random order on a scale ranging from 1 (not at all) to 7 (very much) for each of the following: prototypical White appearance, prototypical Asian appearance, prototypical White features, prototypical Asian features, the neutrality of facial expression, and attractiveness. 
The final set of 12 biracial Asian/White faces (11 East Asian, 1 Southeast Asian ${ }^{1}$ ) did not differ based on participant cultural group (see Appendix 1 for stimuli examples and Appendix 2 for all pre-testing details and results; see https://osf.io/crxja/?view_only=ac48fb205a5949ce88ad6f855eab97e5 for all data).

\section{Experiment 1: Taiwanese Children}

Experiment 1 is among the first studies to investigate racially ambiguous face categorization in a Taiwanese sample using real biracial stimuli. Moreover, racial constancy beliefs to date have also been measured only in the U.S. Here, we test whether racial constancy beliefs also impact Taiwanese children's categorizations of biracial Black/White and Asian/White faces. As stated previously, since in Taiwan, Taiwanese children are a racial majority, combined with that the White racial category serves as as primary salient outgroup compared to the Black racial category ), we expected Taiwanese children would categorize Asian/White stimuli more often as White or as the outgroup and Black/White stimuli also more often as White following IOE expecations. We had no predictions regarding racial constancy beliefs since race is constructed differently in Taiwan than the U.S. and this was the first time using these methods in that context.

\section{Method}

\footnotetext{
1 Following Chen et al. (2021) and Ma et al. (2020), "Asian" as a pan-ethnic term is also used here for both participant and stimuli purposes. We acknowledge there are both phenotypic and identity-based within-group ethnic group differences that should be considered in future research (i.e., differences for South Asian versus East Asian individuals). However, for the goals of the present study, Asian as an overarching group term signifies ingroup or outgroup most clearly.
} 


\section{Participants}

An a priori power analysis was conducted using $\mathrm{G}^{*}$ Power3.1 (Faul et al., 2007) based on the within-subjects design using an expected medium effect size based on the literature (d $=.50$ ), power $\beta=.80$, and an alpha of .05 which projected a minimum sample size of 27 .

However, knowing that racial constancy endorsements in U.S. samples tend to come online around the ages of 5-6 years (Gaither et al., 2014; Pauker et al., 2010), we wanted enough children across the targeted years of ages 3-7 to ensure variability in racial constancy understandings. Thus, a total of 81 children were recruited either through the Infant/Child participant database housed by the Infant Perceptual Developmental Laboratory $(n=47)$ or via recruitment flyers distributed at local kindergartens $(n=34)$. Each participant received 350 NTD, a toy, and an award certificate for participation. All children were asked to categorize both biracial Asian/White and Black/White faces following a within-subjects design (counterbalanced on which stimuli children saw first). Seven children were excluded from Asian/Whitestimuli analyses for not completing the categorization task, resulting in a final sample of 74 children (39 female; age range 3-6 years, $M_{\text {age }}=5.08$ years, $S D=1.08$ ) for the Asian/White stimuli. Similarly, five other children were excluded from Black/White stimuli analyses for not completing that task, resulting in a final sample of 76 children (40 female; age range 3-6 years, $M_{\text {age }}=5.04$ years, $S D=1.07$ ) for the Black/White stimuli. All children were East Asian and had normal or corrected-to-normal vision (20/20). 
Socioeconomic status on annual income was collected from most parents, $5 \%$ are under $\$ 450,000 \mathrm{NTD}, 42 \% \$ 450,001-\$ 900,000 \mathrm{NTD}$, and 53\% are from families making $\$ 900,000$ NTD or more. Both parental consent and child verbal assent for participation were obtained prior to the study. All methods were approved by the Research Ethics Committee of (masked for review).

\section{Stimuli and Procedures}

All participants completed the racial categorization tasks and then a racial constancy task in a fixed order. A within-subject design was adopted; thus, all participants categorized both biracial Black/White and biracial Asian/White faces but in a counter-balanced order across all participants. There was a 3-5-minute break between the first and the second categorization blocks. The racial constancy task was administered after the categorization task. On average, each session lasted around 45 minutes.

Racial Categorization Task. Children sat in a chair facing a laptop computer (15.6-inch display; ASUS VivoBook S551L) and were told the following instructions in Mandarin: "You are going to play a face game! Your job is to look at some different faces and tell us who they look more like! We will do a few practice ones and then the real game will start! Are you ready?" Before the target ambiguous face categorization task trials, children completed four practice trials with pre-tested unambiguous monoracial faces to familiarize them with the racial categories and to face categorization task itself. For the practice trials, four monoracial 
faces (two female, two Asian, two White for the Asian/White task; two female, two Black, two White in the Black/White task) were obtained from the Chicago Face Database, which were pre-tested as being prototypical members of their respective racial groups (Ma et al., 2015). Three faces then appeared on the screen - the top face was the target face (either the unambiguous or ambiguous stimuli) and the two bottom faces were the categorization choices (unambiguous White, Black, or Asian faces depending on the categorization task). Children were asked "Who does this face look more like, this face or that face?" (see Figure 1). Thus, children were asked if the target face looked more like a White, Black, or Asian unambiguous face to measure their racial categorizations. Following the practice trials, participants then categorized 12 racially ambiguous faces (six females) that were previously pre-test on ambiguity — either biracial Black/White or biracial Asian/White faces depending on their testing order (see Appendix 1 for sample stimuli). The size of the faces displayed on the screen was $5.7 \mathrm{~cm}$ (height) * $4.1 \mathrm{~cm}$ (width).

Racial Constancy Task. Next, children completed a previously used and validated short three-item racial constancy measurement (Gaither et al., 2014, 2020; Hirschfeld, 1995; Pauker et al., 2010; Ruble et al., 2007; Semaj, 1980). Following past methods exactly to ensure our abilities to test for generalizeability not only between cultural contexts but also in comparison to past work, children were shown three faces (all photos matched to the child's gender): one was either a Black, White, or East Asian child (depending on the condition) 
whose photo was placed above that of a Black, White, or East Asian adult. The experimenter asked in Mandarin: "When this child grows up, will they look more like this adult [e.g., White] or this adult [e.g., Black]?" Next participants viewed a similar array of photos, only here they saw either a Black, White or East Asian adult pictured above a Black, White, or Asian child (again depending on the condition) and the experimenter asked in Mandarin, "When this adult was little, did they look more like this child [e.g., White] or this child [e.g., Black]?" Finally, the experimenter pointed to a picture of the White child and asked in Mandarin: "If this child really wanted to be Black [or Asian depending on the condition] and change his/her skin color, could he/she do that?" The experimenter also asked children to explain why they believed that the child could or could not change his or her racial group membership. Three coders rated all children's responses to this question in order to examine their reasoning and understanding of racial group membership with 100\% agreement.

Following past coding methods, children were coded as endorsing racial constancy beliefs if they (a) made a race match in the first two questions and answered "no" to the last question, indicating that they believe race is both stable across the lifespan and immutable, and (b) used essentialist or fixed reasoning about race as a stable category in their explanation for why someone could not change their skin color by referencing either immutability (e.g., "You are born looking like that way, so they will stay that way forever"), inheritability or biology (e.g., "You stay the same color because that is how you are when you are a baby"), or 
naturalness (e.g., "They can't change their skin, he was made that way"). If children did not provide a reasoning or if that reasoning did not fall into any of the above categories (e.g., "they just feel that way"), they were coded as not having racial constancy beliefs. Thus, children needed to answer all questions correctly and provide essentialist reasoning to be coded as having racial constancy understanding. These methods follow past developmental work demonstrating that using simple dichotomous yes/no responses without an open-ended response limits one's ability to know if a child simply had a yes or no bias (Gimenez \& Harris, 2002; Killen \& Stagnor, 2001; Taylor, Rhodes, \& Gelman, 2009). Importantly, children completed this task twice — once using monoracial Black and White target stimuli (the usual methods for this task in a U.S. context) when completing the Black/White categorization task and once using Asian and White target stimuli when completing the Asian/White categorization task since the Black racial category is not as common for children to see in this context (less than $1 \%$ and only 2,446 in total of the Taiwanese population; Ministry of Interior National Immigration Agency of Taiwan, 2019).

\section{Results}

\section{Asian/White Condition}

First, regarding racial constancy outcomes using the Asian and White target stimuli, 22 children were coded as endorsing racial constancy beliefs ( 9 females, $M_{\text {age }}=5.71, S D=0.83$, age range 3.97-6.85) and 52 children were coded as not having racial constancy beliefs (30 
females, $M_{\text {age }}=4.80, S D=1.04$, range 3.25-6.81). The group of children endorsing racial constancy beliefs were significantly older than those without racial constancy understandings, unlike past work with U.S. samples, $t(72)=4.68, p<.001$, Cohen's $d=1.11$.

To measure categorization outcomes, proportions were calculated by averaging Asian categorizations coded as "1" with White categorizations coded as "0." Thus, an average score ranging from 0 (White bias in categorization) to 1 (Asian bias in categorization) was calculated for each participant. We employed one-sample t-tests to test whether children's categorization tendencies differed from chance. We used independent-sample t-tests to explore whether children's categorization outcomes differed due to the adoption of racial constancy beliefs rather than ANOVAs because of unequal sample sizes and differing experimental design between the Taiwanese (within-subject design) and U.S. samples (between-subject design; see Experiment 2).

Results showed that overall, Taiwanese children did not differ from chance levels when categorizing biracial Asian/White faces, meaning on average they showed no bias on their racial categorizations $(M=0.51, S D=0.20 ; t(73)=0.51 ; p=.31)$. However, when looking at whether the results differed for children with and without racial constancy beliefs, Taiwanese children with racial constancy beliefs were significantly below chance levels $(M=0.43, S D=$ $0.19 ; t(21)=1.77 ; p=.045$, Cohen's $d=0.37)$, meaning they tended to categorize the Asian/White ambiguous faces more often as White (racial outgroup). In contrast, Taiwanese 
children without racial constancy beliefs were significantly above chance levels $(M=0.55$.

$S D=0.20 ; t(51)=1.69, p=.049$, Cohen's $d=0.25)$, meaning they were more likely to categorize the Asian/White ambiguous faces more often as Asian (racial ingroup). A followup analysis confirmed that children with racial constancy beliefs significantly differed in their categorizations compared to children without racial constancy beliefs, $(t(73)=2.19, p=.03$, Cohen's $d=0.56$; see Figure 2).

Since the present results showed that children with racial constancy beliefs were significantly older than those without racial constancy beliefs (unlike past published work with White children), we conducted two further analyses (parametric and non-parametric) to evaluate the possible influence of children's exact age on their categorization outcomes. First, there was no correlation between children's ages and categorization scores $(r=-0.10, p$ $=.41$.) suggesting age itself is not predictive of how Taiwanese children see biracial Asian/White faces. Moreover, a Chi Square test of Independence exploring distributions of categorization tendencies $(<0.5$ : chose White categorizations more often; $=0.5$ : no categorization bias, or $>0.5$ : chose Asian categorizations more often) across the four age groups (3-, 4-, 5-, and 6-year-olds) also showed no association, $X^{2}(6, N=74)=$ $9.644, p=.85$. Thus, we do not believe that age by itself is uniquely predictive of racial categorization outcomes, however this paper also marks the first time these methods have been used with a racial/ethnic minority sample and it is possible that discussions of race and 
culture may shift age outcomes for racial constancy endorsements - a direction for future research.

\section{Black/White Condition}

First, regarding racial constancy outcomes using the Black and White target stimuli, 22 children were coded as endorsing racial constancy beliefs ( 10 females, $M_{\text {age }}=5.73, S D=$ 0.92, age range 3.97-6.85) and 54 children were coded as not having racial constancy understanding (30 females, $M_{\text {age }}=4.69, S D=1.00$, range 3.25-6.81). Similar to the other task, those with racial constancy endorsements were significantly older than those without racial constancy beliefs, $t(74)=4.33, p<.001$, Cohen's $d=1.07$.

When comparing the racial constancy results for children across the Asian and White and Black and White racial constancy task, all of the same children except for four were coded in the same way (i.e., endorsing/not endorsing racial constancy beliefs). This suggests that using either Asian and White or Black and White stimuli both measure the same racial constancy beliefs for Taiwanese children. Importantly, to our knowledge, this is the first time that this method of measuring racial constancy has been used outside of the U.S. in addition to adopting Asian target stimuli to make this task culturally-specific in Taiwan.

To measure categorization outcomes, proportions were calculated by averaging Black categorizations coded as "1" with White categorizations coded as "0." Thus, an average score ranging from 0 (White bias in categorization) to 1 (Black bias in categorization) was 
calculated for each participant. The same analyses as used for the Asian/White stimuli were used here.

Results revealed that Taiwanese children overall were significantly below chance levels when categorizing biracial Black/White faces, meaning they showed a White categorization bias $(M=0.40, S D=0.24 ; t(74)=3.74 ; p<.001$, Cohen's $d=0.41)$. When looking at whether categorization results differed for children with and without racial constancy beliefs, Taiwanese children with racial constancy beliefs were significantly below chance levels $(M=$ $0.36, S D=0.22 ; t(21)=-3.01 ; p=.003$, Cohen's $d=0.63)$, meaning they tended to categorize the Black/White ambiguous faces more often as White (racial outgroup). Differing from the Asian/White condition, Taiwanese children without racial constancy beliefs were also significantly below chance levels $(M=0.42, S D=0.22 ; t(53)=-2.89, p=.003$, Cohen's $d=$ 0.36), meaning they were also more likely to categorize the Black/White ambiguous faces more often as White (racial outgroup). Children with and without racial constancy beliefs did not differ in their categorization outcomes on this task, $t(75)=1.02 ; p=.31$; Cohen's $d=$ 0.26 (see Figure 3). Again, age was not significantly correlated with categorization outcomes, $r=-0.19, p=.10$. Moreover, individual children's Asian/White and Black/White categorization outcomes did not show any correlations with each other, $r=-.04, p=.69$.

\section{Discussion}

Experiment 1 was among the first to investigate racially ambiguous face categorization 
for Taiwanese children and to explore whether racial constancy beliefs also impact Taiwanese children's categorizations of both biracial Black/White and Asian/White faces. Taiwanese children who have adopted racial constancy beliefs are more likely to categorize biracial Asian/White faces as White or as their outgroup, supporting past work with older Taiwanese children (Chen et al., 2019). These results also extend ingroup bias findings cross-culturally (e.g., Dunham et al., 2013) by demonstrating that Taiwanese children, when presented with an ingroup/outgroup categorization choice, exclude an ambiguous group member to their outgroup. However, Taiwanese children were also more likely to categorize biracial Black/White faces as White, regardless of racial constancy beliefs. Although both Black and White reflect outgroup categorizations in this study, these results still provide I.O.E. support because Taiwanese have more direct exposure to White than Black individuals through their media use and English international schools (Chen, 2012; Ministry of Foreign Affairs, 2018), making the White racial category a more salient and dominant outgroup (Leyens \& Yzerbyt, 1992).

Knowing that culture does shape both the conceptual and the perceptual aspects of race as it relates to existing hierarchies (see Chen et al., Dunham, 2018, for race categorization comparisons between the U.S. and Brazil), we next tested these same questions within a U.S. sample. 
Experiment 2 recruited an Asian American sample, which also marks the first time based on our knowledge for racially ambiguous categorization research to recruit Asian American children. In a U.S. context, Asian American children are instead a racial minority (compared to being a majority group in Taiwan), with the White racial category remaining the main salient outgroup. Thus in line with the I.O.E., we expected Asian American children to resemble Taiwanese children regarding Black/White categorization outcomes (categorizing faces more often as White), but we did not have specific predictions for Asian/White categorization outcomes since Asian American children are a lower status ethnic group and based on past work, lower status group members (Black adult participants) when under threat tend to categorize racially ambiguous Black/White faces more often as Black or their ingroup to boost their sense of ingroup belonging (Gaither et al., 2016). Thus, following IOE we would expect Asian American children to categorize Asian/White faces more often as White, but taking status into consideration we would expect more Asian (or ingroup) categorizations. We had no firm predictions regarding racial constancy beliefs since this is the first time racial constancy was measured with an Asian American sample, but expected racial constancy beliefs to be associated with increased outgroup categorizations based on past work.

\section{Method}

\section{Participants}

Our goal was to recruit 60-75 Asian American children in total to have a comparable 
size to the Taiwanese sample following the same power analysis suggestions (i.e., a minimum sample size of 27 using G*Power 3.1; Faul et al., 2007). All children were recruited either from a local science museum $(n=35)$ in exchange for sticker prizes based on museum compensation policies and tested on-site or through a combination of departmental developmental database listings and online advertisements $(n=30)$ in exchange for $\$ 10$ and a small toy for in-lab participation. However, since pilot testing in the U.S. uncovered children not being able to sit through the same within-subjects design as was used in Taiwan, the U.S. study was forced to adopt a between-subjects design that randomly assigned children to complete either the biracial Asian/White categorization task or the biracial Black/White categorization task. Thus, direct comparisons between the Taiwanese and U.S. American sample cannot be statistically compared due to different experimental designs.

It is important to note that Asian Americans only reflect $5 \%$ of the total population in the southern U.S. region in which this study took place, making this particular population extremely difficult to recruit. In total, 73 3-7 year old children were recruited, but five were excluded for not completing the categorization task and three were excluded for being biracial Asian/White, resulting in a final sample of 65 Asian American children (for the biracial Asian/White condition: $n=45 ; 21$ female; 28 East Asian, 17 South Asian; $M_{\text {age }}=$ 5.30 years, $S D=1.43$; for the Black/White condition: $n=20 ; 11$ female; 10 East Asian, 10 South Asian, 1 Middle Eastern, 2 Central Asian; $M_{\text {age }}=5.20$ years, $S D=1.42$ ). 
Unfortunately, when recruiting at the museum, all children from age ranges outside of our targeted 3-7 year-old range were also run in this study based on museum policies, which resulted in an uneven number of children assigned to each categorization task. Additionally, the five excluded children were all from the Black/White task. We attempted to recruit additional children but were unsuccessful across a number of months due to how incredibly underrepresented they are in the Durham, NC region. However, we still feel our sample sizes adds to the literature by being the first to test these methods with an Asian American sample. All children had normal or corrected-to-normal vision (20/20). Although socioeconomic status was not collected from parents, based on other samples recruited in similar formats at our lab we estimate around $11 \%$ are under $\$ 50,000,30 \% \$ 50,001-\$ 75,000$, and $50 \%$ are from families making $\$ 75,000$ or more. Both parental consent and child verbal assent for participation were obtained prior to completing the study. All methods were approved by (masked for review).

\section{Stimuli and Procedures}

All methods and stimuli were the same as in Experiment 1 except that instructions were given in English, the survey was shown on an Ipad Pro, and a between-subjects design was used, meaning that children either categorized biracial Asian/White or biracial Black/White faces. On average, each session lasted around 20 minutes.

\section{Results}




\section{Asian/White Condition}

First, regarding racial constancy outcomes using the Asian and White target stimuli, 8 children were coded as endorsing racial constancy beliefs ( 3 females, $M_{a g e}=6.19, S D=1.36$, range 3.63-7.90), and 37 were coded as not having racial constancy beliefs ( 17 females, $M_{\text {age }}$ $=5.11, S D=1.38$, range 3.14-7.76). As in the Taiwanese sample, children with racial constancy beliefs were significantly older than children without racial constancy knowledge, $t(43)=2.04, p=.047$, Cohen's $d=0.80$.

To measure categorization outcomes, we calculated the proportions in the same way as in Experiment 1, averaging Asian categorizations coded as "1" with White categorizations coded as " 0. " Thus, an average score ranging from 0 (White bias in categorization) to 1 (Asian bias in categorization) was calculated for each participant. The same analyses used in Experiment 1 were used here.

Results revealed that Asian American children overall were at chance levels when categorizing biracial Asian/White faces, meaning that they showed no bias in their racial categorizations $(M=0.52, S D=0.25 ; t(44)=0.61, p=.55)$. Although our sample sizes are small, when looking at whether categorization results differed for children with and without racial constancy beliefs, neither Asian American children endorsing racial constancy beliefs $(M=0.52, S D=0.23, t(7)=0.26, p=.80)$ nor Asian American children without racial constancy beliefs $(M=0.52, S D=0.26 ; t(36)=0.54 ; p=.59)$ showed bias in their 
categorizations. Thus, racial constancy beliefs did not seem to affect categorizing biracial Asian/White faces (see Figure 2) for Asian American children. Children's exact ages again were not correlated with Asian/White categorizations, $r=0.03, p=.85$.

\section{Black/White Condition}

Regarding racial constancy outcomes using the Black and White target stimuli which is the typical format of this task used to date in the U.S., 10 children were coded as endorsing racial constancy beliefs ( 6 females, $M_{\text {age }}=5.80, S D=1.38$, range 3.00-7.89), and 10 did not have racial constancy beliefs ( 5 females, $M_{\text {age }}=4.55, S D=1.09$, range 3.00-6.50). Again, children with racial constancy beliefs were significantly older than children without racial constancy beliefs, $t(18)=2.24, p=.03$, Cohen's $d=1.00$.

To measure categorization outcomes, we calculated the proportions by averaging Black categorizations coded as "1" with White categorizations coded as "0." Thus, an average score ranging from 0 (White bias in categorization) to 1 (Black bias in categorization) was calculated for each participant. The same analyses were use here as the other condition and as in Experiment 1.

Results revealed that Asian American children overall were significantly below chance levels when categorizing biracial Black/White faces, meaning they showed a White ${\text { categorization } \operatorname{bias}^{2}}^{2}(M=0.30, S D=0.20 ; t(19)=4.36 ; p<.001$, Cohen's $d=1.0)$. When

\footnotetext{
${ }^{2}$ Since the sample size is relatively small in this condition, we analyzed the distribution of the individual children to reassure that the White categorization bias was not due to a few extremely low scorers. Among the 20 children, 12 were below $0.33,7$ were between $0.34 \sim 0.66$, and only 1 child scored 0.67 (this was also the
} 
looking at whether categorization results differed for children with and without racial constancy beliefs, both Asian American children with racial constancy knowledge levels $(M=$ $0.33, S D=0.22 ; t(9)=2.47 ; p=.03$, Cohen's $d=0.77)$ and without racial constancy knowledge were significantly below chance levels $(M=0.28, S D=0.19 ; t(9)=3.70 ; p$ $=.004$, Cohen's $d=1.15)$, meaning Asian American children regardless of racial constancy beliefs tended to categorize biracial Black/White faces more often as White (their racial outgroup). Children with and without racial constancy beliefs did not differ in their categorization outcomes $(t(18)=0.45 ; p=.65)$. This pattern of results echoes Taiwanese children's categorization of biracial Black/White faces in that both cultural groups saw these faces more often as White (see Figure 3). Similarly, age was not correlated with Black/White categorization outcomes, $r=-0.22, p=.82$.

\section{Discussion}

Like Taiwanese children in Experiment 1, here Asian American children also categorized biracial Black/White faces more often as White, supporting the I.O.E. since White is the most dominant outgroup in an American context (Leyens \& Yzerbyt, 1992). However, unlike Taiwanese children, Asian American children had no categorization bias for biracial Asian/White stimuli — they were equally likely to see a biracial Asian/White face as Asian or White, with racial constancy beliefs playing no role. We believe this might be due to 
the fact that although Asian American individuals are considered a higher status "model minority" group in the U.S. (Zou \& Cheryan, 2017), young ethnic minority children often show decreased levels of racial ingroup identification because of constantly considering the views from the dominant, majority society which differs drastically from children in Taiwan (e.g., Ocampo et al., 1997; Spencer \& Markstrom-Adams, 1990). Thus, Asian American children may simply lack the same levels of racial ingroup biases as they learn to navigate living as a minority group within a White majority society which may shift their views of including racially ambiguous others as their ingroup (or Asian). Therefore, both the diversity of one's social context in addition to one's social status may make certain racial categories more and less cognitively accessible (e.g., Chen et al., 2018; Pauker et al., 2015), influencing how one sees ambiguous ingroup and outgroup members.

\section{General Discussion}

To our knowledge, this is the first cross-cultural child exploration of ambiguous biracial face categorization and the first time these methods have been tested with both an Eastern (Taiwan) and a Western (U.S.) sample of Asian children. Importantly, our data suggest hyperdescent over the more commonly cited hypodescent categorization tendence for biracial Black/White stimuli-a finding that generalizes in both cultural contexts. However, biracial Asian/White stimuli may be perceived in more fixed-like patterns in predominately Asian contexts, since only Taiwanese children showed increased outgroup categorizations once racial constnacy 
beliefs were endorsed. Importantly, White U.S. children have also showed increased outgroup categorizations for Black/White biracial stimuli after obtaining racial constancy beliefs

(Gaither et al., 2014), suggesting a potential commonality for majority or high status children. Interestingly, Asian American children showed no perceptual bias for biracial Asian/White faces regardless of racial constancy beliefs, suggesting that both one's context and one's racial or cultural group membership may dictate how and when racial boundaries are drawn (e.g., Chen, 2019; Chen et al., 2018; Pauker et al., 2015, 2018). Importantly, although we did not explicitly measure whether Taiwanese and Asian American children knew they were either a numerical majority or minority group member, it is clear that Asian American children in North Carolina are seeing these faces differently than Taiwanese children. Thus, knowing that racial and ethnic minority children in the U.S. do not develop ingroup biases as early as White (majority) children due to their experienced conflict between the positive attitudes they hold for their own group in contrast to the "White is good" positive assoications espoused toward the majority group (e.g., Spencer \& Markstrom-Adams, 1990), we could interpret the lack of a categorization bias for Asian/White faces as a sign of increased cognitive flexibility for Asian American children.

\section{Constraints on Generality and Future Directions}

Although not measured directly in this set of studies, Taiwan and the U.S. reflect different cultural contexts. Taiwanese children grow up within a collectivisitc culture which 
may explain why they show a stronger outgroup categorization bias compared to Asian American children in the U.S.- they want to protect their established group. In contrast, Asian American children may have learned both individualistic and collectivistic tendencies through their upbringing and socialization, making their bicultural existence a possible explanation for the lack of an Asian/White categorization bias (e.g., Masuda \& Nisbett, 2001), since they may have more flexible and/or variable approaches in how they perceive ambiguous group members. In fact, Triandis (1995) argued that prejudice and discrimination are more likely among collectivists than individualists for this reason. Thus, future work should measure assimilation rates and cultural beliefs within Asian American samples to directly measure different motivations in ambiguous categorizations. Additionally, our sample size was too small to statisically examine within-ethnic-group differences (Zhou; 1997; Zou \& Cheryan, 2017). We would predict that being East Asian versus South Asian may also lead to different facial cues being used during ambiguous categorization due to the varying phenotypic or skin tone cues salient to each group. Although our stimuli set did include a few faces of South Asian descent, our stimuli set is not large enough to statistically analyze for those within ethnic group differences.

Regarding the universality of both Taiwanese and Asian American children categorizing biracial Black/White faces more often as White, future work should more directly measure both the exact motivations that children may be using during categorization tasks. In line with 
category cognitive accessibility differences (Chen \& Hamilton, 2012), the "Black" racial category may not be as cognitively accessible for Taiwanese children due to their homogeneous cultural context, but the "Black" category should be more readily accessible in a U.S. context. However, Asian American children show the same hyperdescent outcomes (White categorizations) as Taiwanese children. We argue that these outcomes are more likely reflective of long-standing cultural conventions that highlight White individuals as the positive high status outgroup through experiences of socialization in both contexts (Hirshfeld, 1998; Markus \& Kityama, 2010).

Future work should explicitly test if Asian American children living within contexts with a higher percentage of other Asian individuals (e.g., Seattle, Washington or Hawaii) instead might categorize Asian/White biracial faces more often as White. This would suggest that increased exposure to ingroup members in a racially stratified society may strengthen the formation of exclusionary categorization biases, which would expand existing definitions and contexts thought to contribute to processes such as the I.O.E. and hypodescent.

\section{Conclusions}

In sum, this work is among the first to extend the racially ambiguous categorization research to both an eastern sample of Taiwanese children cross-culturally, in addition to testing ambiguous categorization processes with Asian American children (e.g., Chen, 2019; Pauker et al., 2018). Our results highlight both cultural similarities and differences in how 
young Taiwanese and Asian American children draw their racial boundaries, suggesting that the social construction of race and the social context are both factors, at least when the categorization choice at hand reflects an ingroup versus outgroup designation. What is clear is that there is variability in how and when these racial boundaries are drawn. Thus, this work pushes the need for racial categorization research in more international contexts while also sparking the necessity for more developmental research with representative samples. 


\section{References}

Andrade, T. (2010). How Taiwan became Chinese: Dutch, Spanish, and Han Colonization in the seventeenth century. The China Quarterly, 203, 725-763.

Blascovich, J., Wyer, N.A., Swart, L., \& Kibler, J.L. (1997). Racism and racial categorization. Journal of Personality and Social Psychology, 72, 1364-1372. https://doi.org/10.1037/0022-3514.72.6.1364

Chao, M. M., Hong, Y., \& Chiu, C. (2013). Essentializing race: Its implications on racial categorization. Journal of Personality and Social Psychology, 104, 619-634. https://doi.org/10.1037/a003133

Chen, C. F. (2012). Rethinking the communication rights of international migrant workers/immigrants: A local perspective. Taiwanese Journal of Communication Research and Practice, 2(1), 55-84.

Chen, J. M., Norman, J. B., \& Nam, Y. (2021). Broadening the stimulus set: introducing the American multiracial faces database. Behavior Research Methods, 53(1), 371-389. https://doi.org/10.3758/s13428-020-01447-8

Chen, C. M., Yang, S. F., \& Chien, S. H.L. (2016). Exploring the own-race face encoding advantage and the other-race face categorization bias in Taiwanese adults: Using a morphing face paradigm. Chinese Journal of Psychology, 58(2), 39-53. https://doi.org/10.6129/ CJP.20160329 
Chen, C. M., Kuo, Y, S., \& Chien, S. H.L. (2019). Asian or Caucasian? Exploring the development of race categorization in Taiwanese school-age children with a morphing face paradigm. Chinese Journal of Psychology, 61(2), 151-172. https://doi.org/10.6129/CJP.201906_61(2).0004

Chen, J. M. (2019). An integrative review of impression formation processes for multiracial individuals. Social and Personality Psychology Compass, 13(1), e12430. https://doi.org/10.1111/spc3.12430

Chen, J. M., \& Hamilton, D. L. (2012). Natural ambiguities: Racial categorization of multiracial individuals. Journal of Experimental Social Psychology, 48(1), 152-164. https://doi.org/10.1016/j.jesp.2011.10.005

Chen, J. M., de Paula Couto, M. C. P., Sacco, A. M., \& Dunham, Y. (2018). To be or not to be (black or multiracial or white) cultural variation in racial boundaries. Social Psychological and Personality Science, 9 (7), 763-772. https://doi.org/10.1177/1948550617725149

Davis, F. J. (1991). The one-drop rule defined. Who is Black? One Nation's definition. University Park: Pennsylvania State University Press.

Dikötter, F. (1992). The discourse of race in modern China. Hurst \& Co. Publishers Ltd Dikötter, F. (1997). The construction of racial identities in China and Japan. Hong Kong University Press. 
Dunham, Y., Chen, E. E., \& Banaji, M. R. (2013). Two signatures of implicit intergroup attitudes: Developmental invariance and early enculturation. Psychological Science, 24(6), 860-868. https://doi.org/10.1177/0956797612463081

Dunham, Y., Stepanova, E. V., Dotsch, R., \& Todorov, A. (2015). The development of racebased perceptual categorization: Skin color dominates early category judgments. Developmental Science, 18(3), 469-483. https://doi.org/10.1111/desc.12228

Dunham, Y., Dotsch, R., Clark, A. R., \& Stepanova, E. V. (2016). The development of WhiteAsian categorization: Contributions from skin color and other physiognomic cues. PloS one, 11(6), e0158211. https://doi.org/10.1371/journal.pone.0158211

Durham County, NC - Population by Race. (2016). Demographics. Retrieved from https://durhamnc.gov/DocumentCenter/View/12985.

Faul, F., Erdfelder, E., Lang, A. G., \& Buchner, A. (2007). G*Power 3: A flexible statistical power analysis program for the social, behavioral, and biomedical sciences. Behavior Research Methods, 39, 175-191. https://doi.org/10.3758/BF03193146

Freeman, J.B., Pauker, K., Apfelbaum, E.P., \& Ambady, N. (2010). Continuous dynamics in the real-time perception of race. Journal of Experimental Social Psychology, 46, 179185. https://doi.org/10.1016/j.jesp.2009.10.002

Freeman, J. B., Pauker, K., \& Sanchez, D. T. (2016). A perceptual pathway to bias: Interracial exposure reduces abrupt shifts in real-time race perception that predict mixed-race 
bias. Psychological Science, 27, 502-517. https://doi.org/10.1177/0956797615627418

Fu, G., Hu, C. S., Wang, Q., Quinn, P. C., \& Lee, K. (2012). Adults scan own-and other-race faces differently. PloS one, 7(6), e37688.

Gaither, S. E., Perlin, J. D., \& Doan, S. N. (2020). Race, Gender, and the Development of Cross-Race Egalitarianism. Frontiers in Psychology, 11, 1525. https://doi.org/10.3389/fpsyg.2020.01525

Gaither, S. E., Schultz, J. R., Pauker, K., Sommers, S. R., Maddox, K. B., \& Ambady, N. (2014). Essentialist thinking predicts decrements in children's memory for racially ambiguous faces. Developmental Psychology, 50(2), 482-488.

https://doi.org/10.1037/a0033493

Gaither, S. E., Chen, J. M., Pauker, K., \& Sommers, S. R. (2019). At face value: Psychological outcomes differ for real vs. computer-generated multiracial faces. The Journal of Social Psychology, 159(5), 592-610. https://doi.org/10.1080/00224545.2018.1538929

Gaither, S. E., Pauker, K., Slepian, M. L., \& Sommers, S. R. (2016). Social belonging motivates categorization of racially ambiguous faces. Social Cognition, 34(2), 97-118. https://doi.org/10.1521/soco.2016.34.2.97

Gelman, S.A. (2003). The essential child: Origins of essentialism in everyday thought. Oxford, UK: Oxford University Press. 
Gimenez, M., \& Harris, P.L. (2002). Understanding constraints on inheritance: evidence for biological thinking in early childhood. British Journal of Developmental Psychology, 20, 307-324. doi:10.1348/026151002320620262

Halberstadt, J., Sherman, S. J., \& Sherman, J. W. (2011). Why Barack Obama is black: A cognitive account of hypodescent. Psychological Science, 22, 29-33. https://doi.org/10.1177/0956797610390383

Henrich, J., Heine, S.J., \& Norenzayan, A. (2010). The weirdest people in the world? Behavioral and Brain Sciences, 33, 61-83. https://doi.org/10.1017/S0140525X0999152X

Higgins, E. T. (1996). Activation: Accessibility, and salience. Social psychology: Handbook of Basic Principles, 133-168.

Hirschfeld, L. A. (1995). Do children have a theory of race?. Cognition, 54(2), 209-252. https://doi.org/10.1016/0010-0277(95)91425-R

Ho, A. K., Roberts, S. O., \& Gelman, S. A. (2015). Essentialism and racial bias jointly contribute to the categorization of multiracial individuals. Psychological Science, 26(10), 1639-1645. https://doi.org/10.1177/0956797615596436

Ho, A. K., Sidanius, J., Levin, D. T., \& Banaji, M. R. (2011). Evidence for hypodescent and racial hierarchy in the categorization and perception of biracial individuals. Journal of Personality and Social Psychology, 100, 492-506. https://doi.org/10.1037/a0021562 
Ho, A. K., Sidanius, J., Cuddy, A. J., \& Banaji, M. R. (2013). Status boundary enforcement and the categorization of Black-White biracials. Journal of Experimental Social Psychology, 49, 940-943. https://doi.org/10.1016/j.jesp.2013.04.010

Hung, M. K. (2021). Teaching the US civil rights movement and its legacy in Taiwan: an exploration of racial awareness in a Taiwanese high school class. Asian Ethnicity, 1-21.

Hsu, P. C., Hsiung, E. Y., \& Chien, S.H.L. (2017, July). Not all races are preferred equally: Exploring the development of race-based social preferences in Taiwanese children. Poster presented at the 13th Asia-Pacific Conference on Vision (APCV), Tainan, Taiwan. Jones, N.A., Bullock J. The two or more races population: 2010. United States Census Bureau, C2010BR-13. 2012:1-24. Retrieved from https://www.census.gov/prod/cen2010/briefs/c2010br-13.pdf.

Killen, M., \& Stangor, C. (2001). Children's social reasoning about inclusion and exclusion in gender and race peer groups contexts. Child Development, 72, 174-186. https://doi.org/10.1111/1467-8624.0027

Lan, P. C. (2011). White privilege, language capital and cultural ghettoisation: Western highskilled migrants in Taiwan. Journal of Ethnic and Migration Studies, 37(10), 1669-1693.

Lee, K., Wang, Q., Fu, G., Xiao, N., Hu, C., \& Quinn, P. C. (2013). Categorizing racially ambiguous faces as own-versus other-race influences how those faces are scanned. Journal of Vision, 13(9), 985-985. 
Leonardelli, G. J., Pickett, C. L., \& Brewer, M. B. (2010). Optimal distinctiveness theory: A framework for social identity, social cognition, and intergroup relations. Advances in Experimental Social Psychology, 43, 63-113. https://doi.org/10.1016/S00652601(10)43002-6

Leyens, J. P., \& Yzerbyt, V. Y. (1992). The ingroup overexclusion effect: Impact of valence and confirmation on stereotypical information search. European Journal of Social Psychology, 22(6), 549-569. https://doi.org/10.1002/ejsp.2420220604

Li, Z., Ma, L. J., \& Xue, D. (2009). An African enclave in China: The making of a new transnational urban space. Eurasian Geography and Economics, 50(6), 699-719.

Ma, D. S., Correll, J., \& Wittenbrink, B. (2015). The Chicago face database: A free stimulus set of faces and norming data. Behavior Research Methods, 47(4), 1122-1135. https://doi.org/10.3758/s13428-014-0532-5

Ma, D.S., Kantner, J. \& Wittenbrink, B. Chicago Face Database: Multiracial expansion. Behav Res (2020). https://doi.org/10.3758/s13428-020-01482-5

Macrae, C. N., \& Bodenhausen, G. V. (2001). Social cognition: Categorical person perception. British Journal of Psychology, 92(1), 239-255. https://doi.org/10.1348/000712601162059

Maddox, K.B., \& Gray, S. (2002). Cognitive representations of African Americans: reexploring the role of skin tone. Personality and Social Psychological Bulletin, 28, 250- 
259. https://doi.org/10.1177/0146167202282010

Maner, J. K., Miller, S. L., Moss, J. H., Leo, J. L., \& Plant, E. A. (2012). Motivated social categorization: Fundamental motives enhance people's sensitivity to basic social categories. Journal of Personality and Social Psychology, 103, 70-83. https://doi.org/10.1037/a0028172

Markus, H. R., \& Kitayama, S. (2010). Cultures and selves: A cycle of mutual constitution. Perspectives on Psychological Science, 5, 420-430.

https://doi.org/10.1177/1745691610375557

Masuda, T., \& Nisbett, R. E. (2001). Attending holistically versus analytically: comparing the context sensitivity of Japanese and Americans. Journal of Personality and Social Psychology, 81(5), 922-934. https://doi.org/10.1037/0022-3514.81.5.922

Medin, D.L., \& Ortony, A. (1989). Psychological essentialism. In: Vosniadou S, Ortony A, editors. Similarity and analogical processing. New York: Cambridge University Press; pp. 179-195.

Ministry of Foreign Affairs, Republic of China (2018). About Taiwan: People. Retrieved from https://www.taiwan.gov.tw/about.php

Navarrete, C. D., Kurzban, R., Fessler, D. M. T., \& Kirkpatrick, L. A. (2004). Anxiety and intergroup bias: Terror management or coalitional psychology? Group Processes and Intergroup Relations, 7, 370-397. https://doi.org/10.1177/1368430204046144 
Nielsen, M., Haun, D., Kärtner, J., \& Legare, C. H. (2017). The persistent sampling bias in developmental psychology: A call to action. Journal of Experimental Child Psychology, 162, 31-38. https://doi.org/10.1016/j.jecp.2017.04.017

Ocampo K, Knight G, Bernal M. (1997). The development of cognitive abilities and social identities in children: the case of ethnic identity. International Journal of Behavioural Development, 21, 479-500. https://doi.org/10.1080/016502597384758

Pauker, K., Ambady, N., \& Apfelbaum, E. P. (2010). Race salience and essentialist thinking in racial stereotype development. Child Development, 81(6), 1799-1813. https://doi.org/10.1111/j.1467-8624.2010.01511.x

Pauker, K., Meyers, C., Sanchez, D. T., Gaither, S. E., \& Young, D. M. (2018). A review of multiracial malleability: Identity, categorization, and shifting racial attitudes. Social and Personality Psychology Compass, 12(6), e12392. https://doi.org/10.1111/spc3.12392

Pauker, K., Williams, A., \& Steele, J. R. (2016). Children's racial categorization in context. Child Development Perspectives, 10, 33-38. https://doi.org/10.1111/cdep.12155

Plaks, J. E., Malahy, L. W., Sedlins, M., \& Shoda, Y. (2012). Folk beliefs about human genetic variation predict discrete versus continuous racial categorization and evaluative bias. Social Psychological and Personality Science, 3, 31-39. https://doi.org/10.1177/1948550611408118 
Pratto, F., Sidanius, J., \& Levin, S. (2006). Social dominance theory and the dynamics of intergroup relations: Taking stock and looking forward. European Review of Social Psychology, 17, 271-320. https://doi.org/10.1080/10463280601055772

Renolds, T. (2020, July 11). To develop international ties, Taiwan must confront Xenophobia. New Bloom Magazine. Retrieved from https://newbloommag.net/tag/xenophobia-in-taiwan/

Roberts, S. O., \& Gelman, S. A. (2015). Do children see in Black and White? Children's and adults' categorizations of multiracial individuals. Child Development, 86(6), 1830-1847. https://doi.org/10.1111/cdev.12410

Roberts, S. O., Ho, A. K., Kteily, N., \& Gelman, S. A. (2021). Beyond Black and White: Conceptualizing and essentializing Black-White identity. Cultural Diversity and Ethnic Minority Psychology, Advance Online Publication. https://doi.org/10.1037/cdp0000490

Rothbart, M., \& Taylor, M. (1992). Category labels and social reality: Do we view social categories as natural kinds? In G. R. Semin \& K. Fiedler (Eds.), Language and social cognition (pp. 11-36). London, United Kingdom: Sage.

Ruble, D. N., Lurye, L. E., \& Zosuls, K. M. (2007). Pink frilly dresses (P.F.D.) and early gender identity. Princeton Report on Knowledge, 2(2), 2-2.

Semaj, L.T. (1980). The development of racial evaluation and preference: A cognitive approach. The Journal of Black Psychology, 6, 59-79. 
https://doi.org/10.1177/009579848000600201

Skinner, A. L., \& Nicolas, G. (2015). Looking Black or looking back? Using phenotype and ancestry to make racial categorizations. Journal of Experimental Social Psychology, 57, 55-63. https://doi.org/10.1016/j.jesp.2014.11.011

Spencer, M.B., \& Markstrom-Adams, C. (1990). Identity processes among racial and ethnic minority children in America. Child Development, 61, 290-310. https://doi.org/10.1111/j.1467-8624.1990.tb02780.x

Stepanova, E.V., \& Strube, M.J. (2012). What's in a face? The role of skin tone, facial physiognomy, and color presentation mode of facial primes in affective priming effects. The Journal of Social Psychology, 152, 212-227. https://doi.org/10.1080/00224545.2011. 597797

Taylor, M., Rhodes, M., \& Gelman, S. (2009). Boys will be boys; cows will be cows: Children's essentialist reasoning about gender categories and animal species. Child Development, 80, 461-481. https://doi.org/10.1111/j.1467-8624.2009.01272 Triandis, H. C. (1995). Individualism and collectivism. Bouder, CO: Westview Press. U.S. Census. (2012). The two or more races population: 2010 (2010 Census Brief). Retrieved from http://www.census.gov/prod/cen2010/briefs/c2010br-13.pdf

Wong, P., Lai, C. F., Nagasawa, R., \& Lin, T. (1998). Asian Americans as a model minority: Self-perceptions and perceptions by other racial groups. Sociological Perspectives, 41(1), 95-118. https://doi.org/10.2307/1389355 
Yee, A. (2016, March). Asian Americans in North Carolina. Institute for Southern Studies.

Retrieved from http://www.ncjustice.org/sites/default/files/Asian-Americans-in-NC2016.pdf.

Young, D. M., Sanchez, D. T., Pauker, K., \& Gaither, S. E. (2020). A meta-analytic review of hypodescent patterns in categorizing multiracial and racially ambiguous targets. Personality and Social Psychology Bulletin, 0146167220941321. https://doi.org/10.1177/0146167220941321

Yzerbyt, V. Y., Leyens, J.-P., \& Bellour, F. (1995). The ingroup overexclusion effect: Identity concerns in decisions about group membership. European Journal of Social Psychology, 25(1), 1-16. https://doi.org/10.1002/ejsp.2420250102

Zhou, M. (1997). Growing up American: The challenge confronting immigrant children and children of immigrants. Annual Review of Sociology, 23(1), 63-95. https://doi.org/10.1146/annurev.soc.23.1.63

Zou, L. X., \& Cheryan, S. (2017). Two axes of subordination: A new model of racial position. Journal of Personality and Social Psychology, 112, 696-717. https://doi.org/10.1037/pspa0000080 


\section{Author's Contribution}

S.E. Gaither and S. Chien conceptualized the study hypotheses and designed the experiments. Data collection was performed by S.G., S.C., S.Neal, and C.Chen. C.C. performed the data analysis under the supervision of S.C. and S.G. All authors drafted the original manuscript. S.G. and S.C. provided critical revisions to the manuscript. All authors approved the final version of the manuscript for submission. 


\section{Asian/White Condition}

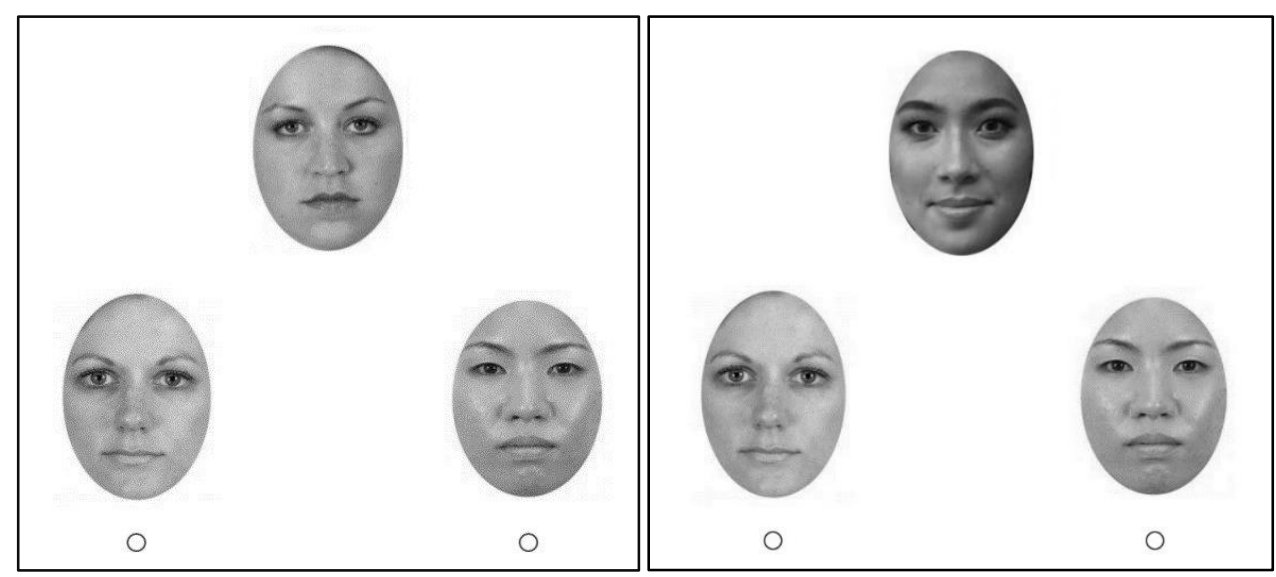

Unambiguous Practice Trial Ambiguous Test Trial

\section{Black/White Condition}

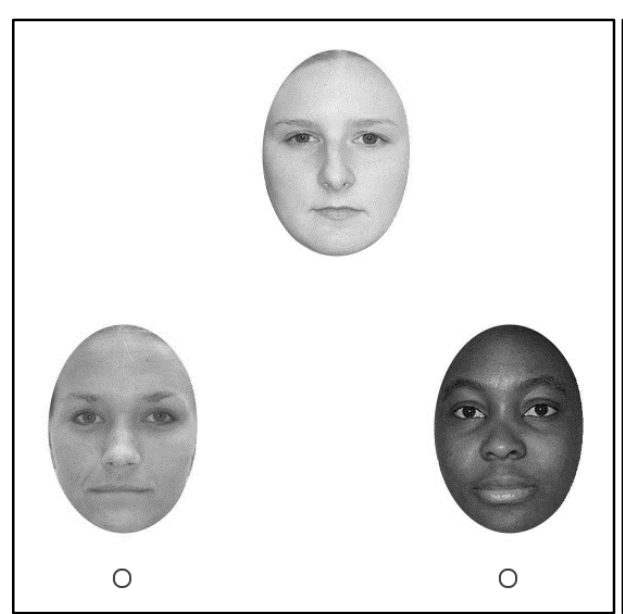

Unambiguous Practice Trial

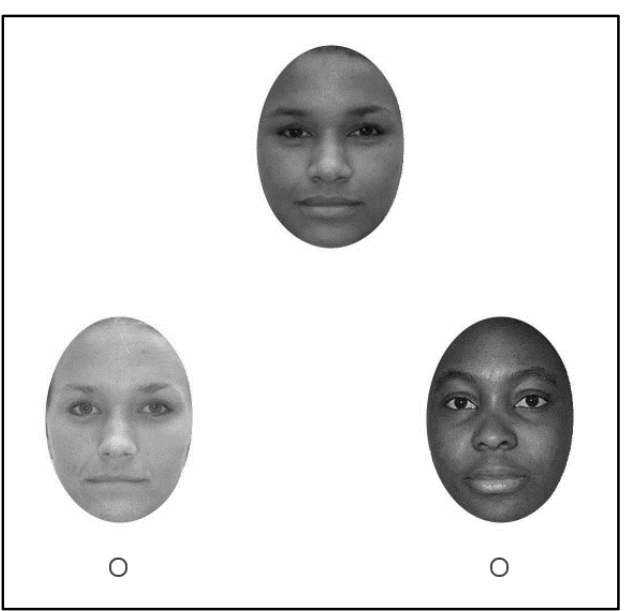

Ambiguous Test Trial

Figure 1. Note. Examples of the trials in the race categorization task. Upper panel: a sample practice trial (left) and a sample test trial (right) of the Asian/White condition. Lower panel: a sample practice trial (left) and a sample test trial (right) of the Black/White condition. All images were shown in color during the studies. 


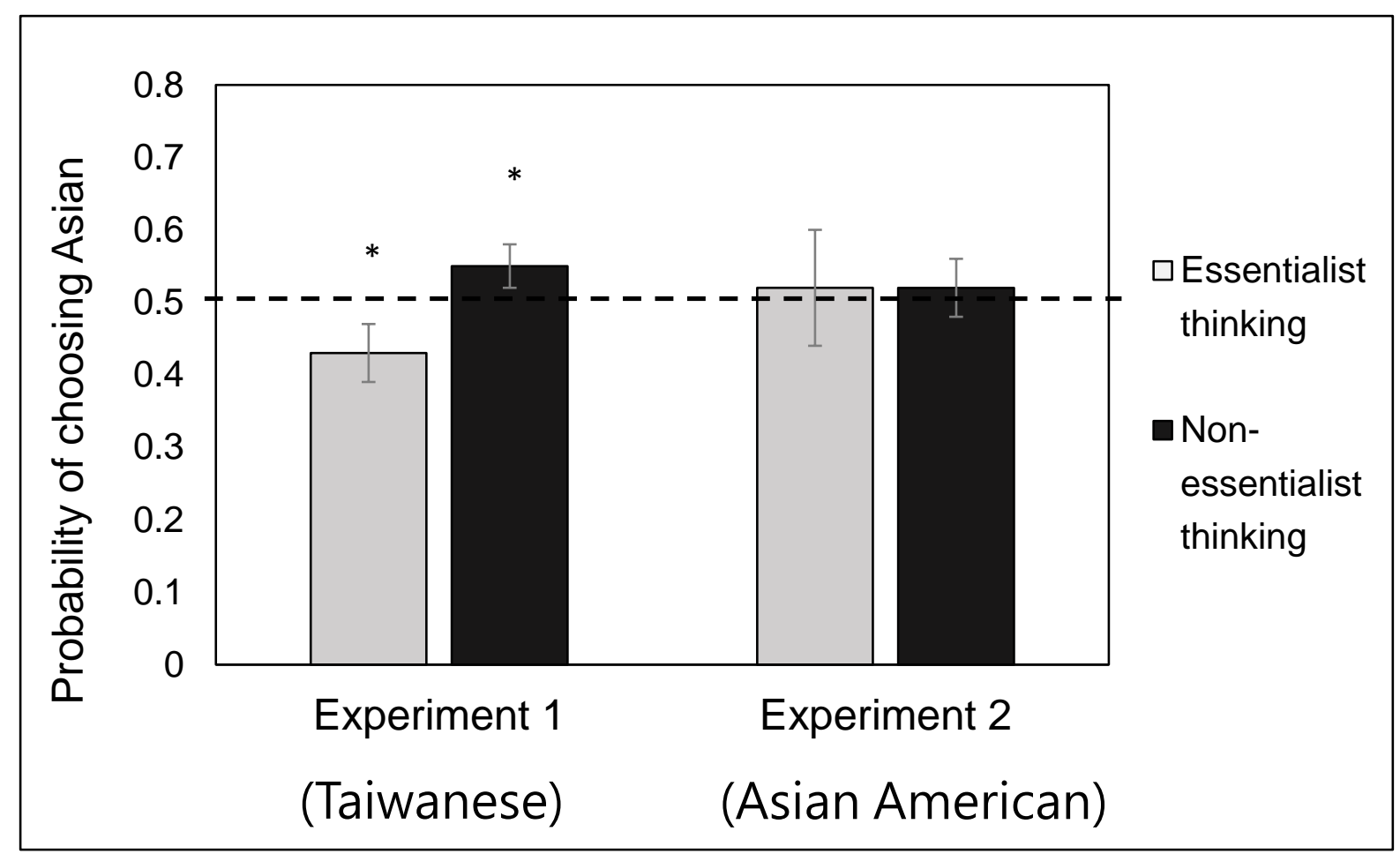

Figure 2. Note. Mean biracial Asian/White categorization outcomes for Taiwanese (Exp. 1)

and Asian American children (Exp. 2). Error bars denote standard errors; dotted line denotes chance levels; asterisk marks a significant difference from chance. 


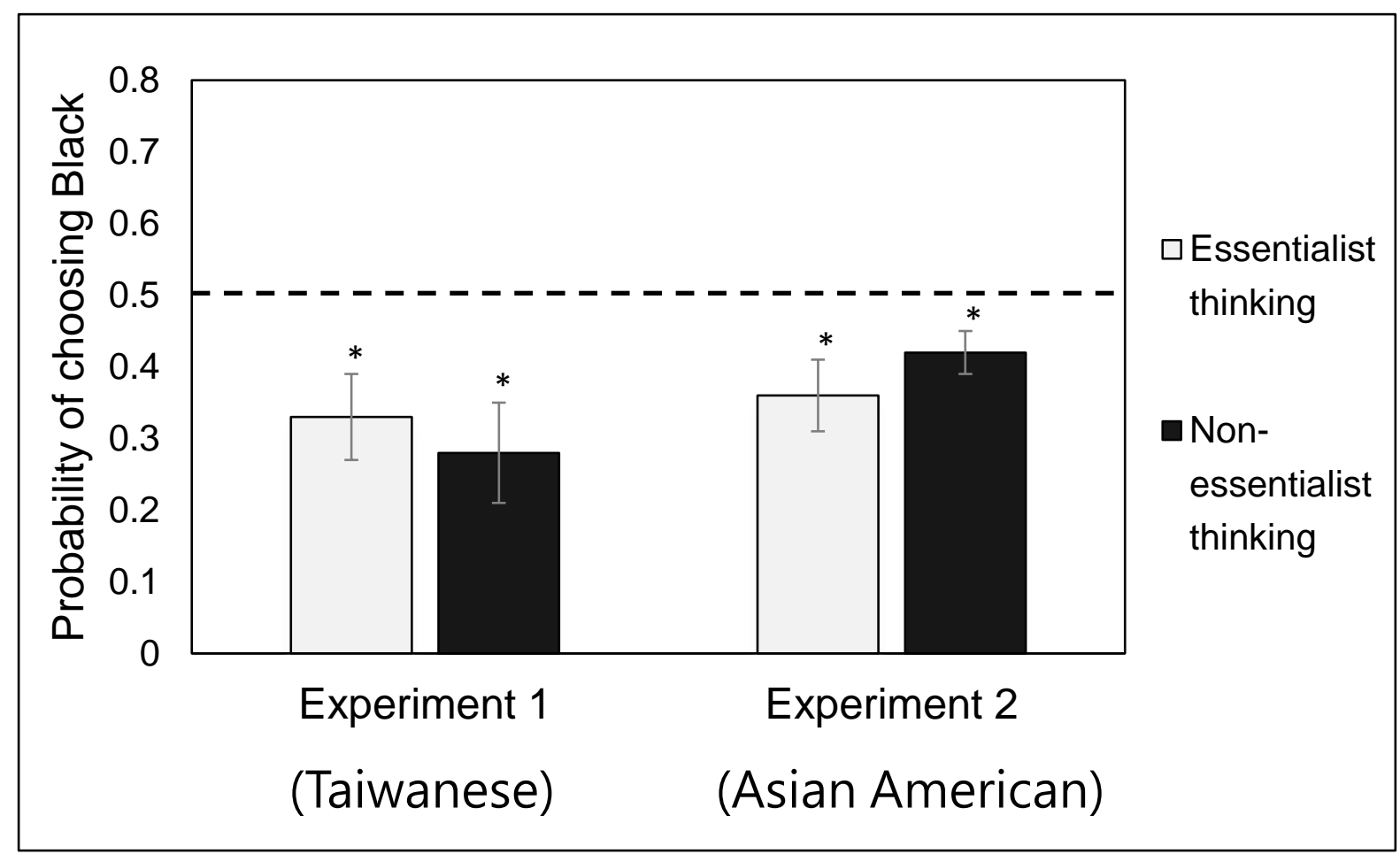

Figure 3. Note. Mean biracial Black/White categorization outcomes for Taiwanese and Asian American children. Error bars denote standard errors; the dotted line denotes chance levels and the asterisk marks a significant difference from chance. 


\section{Appendix 1: Sample Stimuli Faces}

Sample biracial Asian/White ambiguous faces
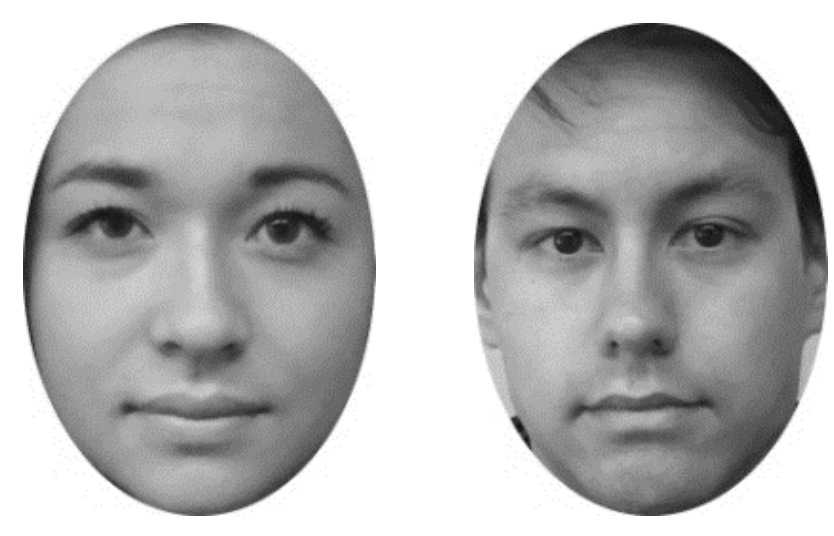

Sample biracial Black/White ambiguous faces
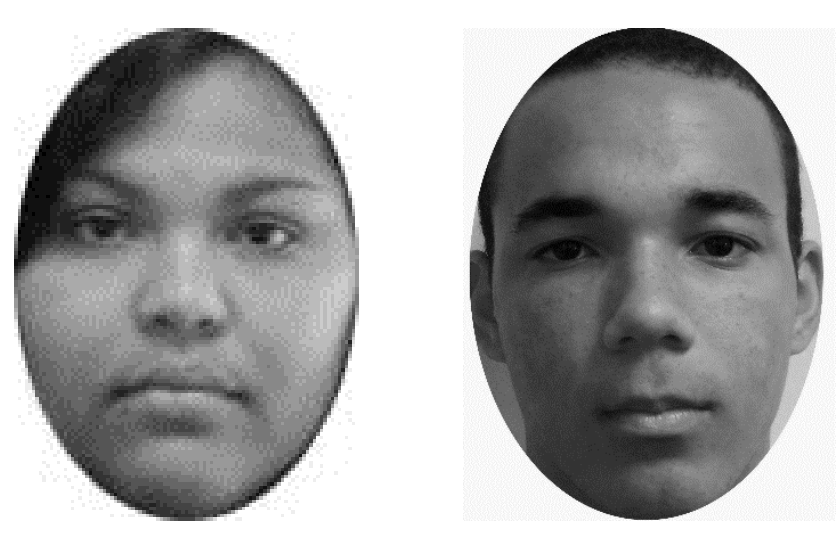

Note. The images were shown in color during the study 


\section{Appendix 2: Biracial Asian/White Stimuli Pretest}

\section{Method}

A total of 39 self-identified biracial Asian/White individuals (23 females; 27 East Asian, 7 Southeast Asian, 5 South Asian) were recruited in the U.S. and photographed in the lab on a white background while making a neutral facial expression. All images were in color and cropped to an oval shape to limit hair and other external features. All images were adjusted to a uniform size and resolution $(184 \times 248$ pixels; $3.8 \times 5.0$ inches $)$. Adult participants in Taiwan and the U.S. were recruited to ensure racial ambiguity for the biracial Asian/White faces was seen equivalently in the two cultural contexts. For the Taiwanese group, 32 adults (16 female; $\left.M_{\text {age }}=39.29, S D=10.69\right)$ were recruited via campus-wide advertisements for a cash payment; the majority of the participants were students at a local university. All participants were native Mandarin speakers and mono-ethnic East Asian. For the U.S. group, 46 adults ( 36 female; $M_{\text {age }}=18.78, S D=0.96 ; 21$ White, 17 Asian, 3 Black, 3 Hispanic/Latino, 2 biracial White/Hispanic) were recruited for class credit; the majority of which were students at a southern U.S. university. This online pretest study was ethically approved by the Research Ethics Committee of (masked for review) and (masked for review)'s I.R.B.

Participants first read the following prompt (either in Mandarin or English): "You will see a series of pictures of different people (39 faces in total). Some of these individuals have 
features that are more typical of White people, and some have features that are more typical of Asian people, in terms of skin color, hair, eyes, nose, cheeks, lips, etc. Please rate the following photos to the best of your ability using your gut or instinctual responses." Participants rated all 39 faces in a random order on a scale ranging from 1 (not at all) to 7 (very much) for each of the following dimensions: prototypical White appearance, prototypical Asian appearance, prototypical White features, prototypical Asian features, the neutrality of facial expression, and attractiveness.

\section{Results}

To determine the 16 most racially ambiguous biracial Asian/White faces, we calculated a mean difference score for each face subtracting ratings for appearing more prototypically White from appearing more prototypically Asian. Therefore, the mean score could range from -6 (appearing more White) to 6 (appearing more Asian), with scores closer to 0 reflecting racial ambiguity between the White and Asian categories (note based on a pretest, the term Asian translated to Mandarin was the best term to use in that context).

Taiwanese participants' mean score across all faces was 0.23 (range $-4.10 \sim 5.08, S D$ $=2.54)$ and a total of 20 of the most ambiguous faces based on these scores were selected, with 10 faces that had positive scores nearest to 0 , and 10 faces that had negative scores that were also nearest to $0(M=0.09$, range $-2.63 \sim 2.88, S D=1.43)$.

U.S. participants' mean score across all faces was 0.15 (range $-3.95 \sim 4.58, S D=2.18$ ). 
Therefore, U.S. and Taiwanese participants did not differ significantly in their perceptions regarding the overall racial ambiguity of the biracial Asian/White faces, $t(77)=0.16, p=.87$, validating our stimuli cross-culturally. We also selected the 20 most ambiguous faces using the same methods as with the Taiwanese participants, with 10 faces that had positive scores nearest to 0 , and 10 faces that had negative scores that were also nearest to $0(M=0.02$, range $-1.99-1.80, S D=1.09)$

Comparing the top 20 faces of each participant group (Taiwan and the U.S.) resulted in 13 overlapping faces ( 5 female, 8 male; $M=0.09, S D=0.25$ in Taiwanese group; $M=-0.14$, $S D=0.78$ in U.S. group) that were rated equally as racially ambiguous by both groups ( $p$ $=.57$ ). We then selected 3 additional female faces based on both participant group's ratings $(M=0.11$, range $-2.00 \sim 1.73, S D=1.16$ for Taiwanese participants; $M=0.01$, range 1.90 1.80, $S D=0.97$ for U.S. participants). This final set of 16 biracial Asian/White faces (11 East Asian, 4 Southeast Asian, 1 South Asian) did not differ based on participant group by attractiveness or neutrality ratings (all $p$ values $>.10$ ). For the present paper, 12 of these biracial faces (11 East Asian, 1 Southeast Asian) were used, and the four additional faces were save for other tasks. 